\title{
FORTIFIGATION OF PASTA WITH BARLEY FRACTION HIGH B-GLUCAN AND QUINOA FLOUR
}

\author{
By \\ Enayat Mahmoud Hassan \\ Food Science Department, \\ Faculty of Agriculture, \\ Cairo University, Giza, Egypt. \\ Sohair Mohamed El-Kayati \\ Food Science and Technology, \\ Plant Production Department, \\ Magda Ibrahim Hassan \\ Food Science Department, \\ Faculty of Agriculture, \\ Cairo University, Giza, Egypt. \\ Mona Mahmoud Abd ELsalam \\ Food Science and Technology, \\ Plant Production Department, \\ Desert Research Center, Cairo, Egypt. Desert Research Center, Cairo, Egypt.
}

Research Gournal Specific Fducation

Faculty of Specific Education

glansoura University

ISSUE NO. 58, APRIL , 2020

مجلة بحوث التربية النوعية - جامعة المنصورة

العدد الثامن والخمسون - أبريل •r.r 


\section{FORTIFICATION OF PASTA WITH BARLEY FRACTION HIGH B-GLUCAN AND QUINOA FLOUR}

Enayat Mahmoud Hassan*

Sohair Mohamed El-Kayati ${ }^{* *}$
Magda Ibrahim Hassan*

Mona Mahmoud Abd ELsalam **

\section{Abstract}

Much attention has been given recently to improve the nutritional value of foods. In this study, the effects of non-traditional flours on cooking quality, texture, composition, and consumer acceptance of pasta were evaluated. Semolina flour used to make pasta was replaced by different ratios of barley fraction enriched with $\beta$-glucan (FD) and quinoa flours. Parameters evaluated in this study were: cooking loss, texture, color values $\left(L^{*}, a^{*}, b^{*}\right)$, proximate composition, amino acid profile, and consumer acceptance. The variables assessed used were the ratios (10, 20 and 30\%) of (FD) or quinoa flour. Also, quinoa flour and FD were used to make pasta at ratios of $(100 \% \mathrm{Q}, 90 \% \mathrm{Q}+10 \% \mathrm{FD}, 80 \% \mathrm{Q}+20 \% \mathrm{FD}$ and $70 \% \mathrm{Q}+30 \%$ FD). Results indicated that pasta containing 30\% FD and 30\% quinoa flours had a decreased optimal cooking time of 11.10 and 5.83 minutes respectively, compared to the control pasta time of 15.17 minutes. Cooking loss was decreased for pasta containing FD and found to be significantly $(\mathrm{p}<0.01)$ greater for pasta containing quinoa flour. Although the addition of quinoa flour negatively affected the cooking loss, the percentages were still found to be at an acceptable level. On the other hand, volume was increased for pasta containing FD or quinoa flour. The results of the texture indicated that hardness and chewiness were significantly $(\mathrm{p}<0.01)$ affected by the addition of non-traditional flours. More so, quinoa flour had a greater effect on hardness and chewiness than FD flour, leading to increased values as more quinoa flour was added. The control pasta was found to be significantly $(p<0.01)$ more firm than those made with FD and quinoa

${ }_{\star \star}^{*}$ Food Science Department, Faculty of Agriculture, Cairo University, Giza, Egypt.

${ }^{\star *}$ Food Science and Technology, Plant Production Department, Desert Research Center, Cairo, Egypt. 
flours, with the exception of S4 and Q4 which contain 30\% FD. Results of the Hunter lab colorimeter indicated that the control pasta was significantly $(\mathrm{p}<0.01)$ lighter than the pastas containing FD and quinoa flours, with those containing the highest amounts of quinoa being the darkest. Redness $\left(\mathrm{a}^{*}\right.$ values) significantly $(\mathrm{p}<0.01)$ increased with the addition of FD and quinoa flours, while yellowness ( $b^{*}$ values) decreased. The yellowness of pastas was found to be affected not only by the addition of FD and quinoa flours, but also by the ratio of the two additional flours. Although statistical analysis could not be performed on the results of proximate composition and amino acid analysis, the results were in agreement with many previous studies. The addition of FD flour greatly increased the protein, fat , fiber, ash, and amino acid content of pasta, with pasta Q4 (70\% Q + 30\% FD) having the highest values of all of these. Accordingly, it can be determined that the addition of quinoa flour and FD had the greatest effect on fortifying wheat pasta. Quinoa pasta (Q1, Q2, Q3 and Q4) had high nutritional value than semolina pasta. Data concluded the possibility of producing pasta relatively higher in fiber, $\beta$-glucan and protein without considerable bad effects on its cooking quality and sensory properties, and also has many benefits for health of diabetes, high cholesterol patients and heart diseases.

\section{Introduction:}

Pasta is a sort of food with high acceptability worldwide because it is a part of the diet of many nations, relatively inexpensive and can be prepared easily (International Pasta Organization, 2011). As a wheat-derived staple food with a very long shelf life, it comes in the second order just after bread in world consumption (Madhumitha, 2011, Duda et. al., 2019). Semolina flour has a limited nutritional profile and is lacking in the amino acids lysine and threonine (Zhao et. al., 2005 \& Gopalakrishnan et. al., 2019). Quinoa and barely are two foods that have been gaining a lot of recognition in the market for their high quality nutritional profile. Quinoa as pseudo-cereal and barley are rich in histidine, lysine and amino acids that traditional semolina flour lack (Mastromatteo et. al., 2011). Both of those foodstuffs can be used to replace or fortify typical durum wheat flour. Fortification of foods has been used by the food industry for years and 
continues to be beneficial in providing consumers with good nutrition (FDA, 1999).

The trend of foods and turning towards products that are naturally high in components with health-promoting effects has boosted that traditionally neglected cereals for human nutrition such as barley, but rich in health-related components, are currently being reconsidered as a part of a healthy human diet (Lahouar et. al., 2016). Barley is the fourth cereal in the world in cultivated area and grows in a wider range of environmental conditions (FAO, 1999). It is mostly cultivated and grows in an appropriate condition. It is rich source of some essential amino acids, minerals such as (Fe, $\mathrm{Zn}, \mathrm{K}, \mathrm{Mg}, \mathrm{Mn}, \mathrm{Se}, \mathrm{P}$ and $\mathrm{Cu}$ ), vitamins ( $\mathrm{B}_{1}, \mathrm{~B}_{2}, \mathrm{~B}_{3}, \mathrm{~B}_{6}$ and folate), useful nutritional polysaccharide. Moreover, it has many classes of phenolic compounds. As well as, barley is considered as suitable source for supplying fiber as $\beta$-glucan (water soluble fiber) Din et. al., (2018) and Jyoti \& Chanu, (2018) that regulates blood glucose level minimize plasma cholesterol levels, also reduce glycemic index and risk of colon cancer. Barley is a cereal that increasingly incorporated in already, used in new food products such as pasta and bread; either as a whole grain or as a food ingredient (Holtekjolen et. al., 2011). Mainly due to the presence of $\beta$-glucan and phenolic compounds which have the potential to lower cholesterol and blood glucose levels (Cavallero et. al., 2002\& Sima et. al., 2018). The benefits of dietary fiber on inflammatory bowel disease may be related to the fermentative production of butyrate in the colon which appears to decrease the inflammatory response (Rose et. al., 2007). Products containing $\beta$-glucan have numerous functional food applications to reduce fat content and calories in a variety of foods (Lee et. al., 2007).

The pasting properties of barley flours also impact textural attributes and consumer acceptance of food product. Because of the importance of viscosity for potential health benefits and sensory attributes understanding the factors which may influence the viscosity of $\beta$-glucans will be beneficial for developing barley-based food products with enhanced health benefits (Jyoti and Chanu, 2018). Costas and Marta, (2007) demonstrated that the 
concentration, molecular weight (MW), and structural features of $\beta$-glucans influence its physical properties (viscosity and solubility).

In addition, barley is gaining renewed interest as an ingredient for production of functional foods due to its high contents of bioactive compounds such as glucans, tocopherols and tocotrienols (Gallegos-Infante et. al., 2010 and Inglett et. al., 2011).

Quinoa (Chenopodium quinoa Willd) is usually referred to as a pseudo-cereal since it is not a member of the Gramineae family, but it produces seeds that can be milled into flour and used as a cereal crop. The embryo can hold $60 \%$ of the seed weight and it forms a ring around the endosperm that loosens when the seed is cooked (National Research Council, 1989). Quinoa contains a complete protein. It is high in essential amino acids, fatty acids. It's a good source of vitamin C, E and several of the vitamins B (Jancurova et. al., 2009). Quinoa contains between14 and 18\% protein, with characteristics similar to milk protein. It is also a source of calcium, magnesium, zinc and iron (Jyoti and Chanu, 2018).

The objective of this research is to prepare pasta products fortified with barley fraction D (FD) (high $\beta$-glucan) and quinoa flour for producing pasta with high nutritional value and more acceptable product.

\section{MATERIALS AND METHODS}

\section{Materials:}

Hull-less barley grains (Giza 129) and Quinoa, Chenopodium quinoa Willd (Regalona cultivar) were obtained from field crops, Raas Sedr Research, Desert Research Center of Egypt. Semolina (Durum wheat semolina type A, 14.5\% moisture) was obtained from El-Maleka Company for food industry, Egypt. Turmeric (curcuma longa), as a color and other ingredients were obtained from local market. Guar gum and vit.C were obtained from Alpha Zyme Company, El-Asher of Ramadan, Sharkiya, Egypt. 
Methods:

Fifty kilograms of Barley were hulled by using barley huller, ground, then fractionated into four fractions A, B, C and D according to the method described by Knuckles, et. al., (1992) at Desert Research Centre, Cairo, Egypt.

Thirty kilograms of Quinoa grains were washed many times with hot water to remove the hulls and saponins until there was no more foam in washing water according to the method of Atef et. al., (2014), then dried at $50^{\circ} \mathrm{C}$. The quinoa seeds were ground to fine powder in a stainless steel electric grinder and sifted through a 60 mesh sieve then stored in polyethylene bags at $-18^{\circ} \mathrm{C}$.

\section{Preparation of pasta products:}

Pasta formulas were prepared according to the procedure described by Yousif et. al., (2012) with some modifications. Semolina, barley fraction $\mathrm{D}$ (high $\beta$-glucan) and quinoa flour, salt, turmeric, (as color), guar gum and vitamin $\mathrm{C}$ were mixed with water in different rates as shown in Table (1). Pregelatinized starch was added to quinoa pasta. After mixing, the dough was pressed into an initial dough sheet by passage through the rolls of the laboratory machine (Titania, 1932, 10024 Moncalieri). The final dough sheet had a thickness of $1 \mathrm{~mm}$ immediately after sheeting; the dough sheet was cut into $5 \mathrm{~mm}$-wide noodles strips.

Drying process: the pasta was dried by using the method described by Lucia et. al., (2011) with some modifications, the process conditions was applied to the following steps:

- Step 1: time $20 \mathrm{~min}$ at $50{ }^{\circ} \mathrm{C}$.

- Step 2: time 6 hours at $80{ }^{\circ} \mathrm{C}$,

- Step 3: over night at room temperature $(19-20){ }^{\circ} \mathrm{C}$. 
- Fortification Of Pasta With Barley Fraction High B-Glucan And Quinoa Flour

Table (1): The prepared different pasta formulas.

\begin{tabular}{|c|c|c|c|c|c|c|c|c|c|c|c|}
\hline \multirow{2}{*}{\begin{tabular}{|c|} 
Ingredients \\
$(\%)$ \\
\end{tabular}} & \multicolumn{7}{|c|}{ Semolina formulas } & \multicolumn{4}{|c|}{ Quinoa formula } \\
\hline & S1 & S2 & S3 & S4 & S5 & S6 & S7 & Q1 & Q2 & Q3 & Q4 \\
\hline Flour & 51.45 & 43.45 & 41.35 & 39.85 & 50.85 & 51.05 & 51.45 & 74.60 & 74.60 & 74.60 & 75.40 \\
\hline Guar & 01.50 & 01.50 & 01.00 & 00.50 & 01.50 & 01.50 & 01.50 & 03.00 & 3.00 & 02.00 & 02.00 \\
\hline Salt & 02.00 & 02.00 & 02.00 & 02.00 & 02.00 & 02.00 & 02.00 & 02.00 & 02.00 & 02.00 & 02.00 \\
\hline Vit.C & 00.05 & 00.05 & 00.05 & 00.05 & 00.05 & 00.05 & 00.05 & 00.10 & 00.10 & 00.10 & 00.10 \\
\hline water & 45.00 & 53.00 & 55.60 & 57.60 & 45.60 & 45.40 & 45.00 & 15.40 & 15.40 & 15.40 & 14.60 \\
\hline Starch & ---- & --- & --- & ---- & --- & --- & ---- & 10.00 & 10.00 & 10.00 & 10.00 \\
\hline \multicolumn{3}{|c|}{$\mathrm{S}_{1}=100 \%$ semolina } & \multicolumn{4}{|c|}{$\mathrm{S}_{2}=90 \%$ semolina $+10 \%$ F.D } & \multicolumn{5}{|c|}{$\mathrm{S}_{3}=80 \%$ semolina $+20 \%$ F.D } \\
\hline \multirow{2}{*}{\multicolumn{3}{|c|}{$\begin{array}{l}S_{4}=70 \% \text { semolina }+30 \% \mathrm{FD} . \\
\mathrm{S}_{7}=70 \% \text { semolina }+30 \% \text { quinoa }\end{array}$}} & \multicolumn{4}{|c|}{$\mathrm{S}_{5}=90 \%$ semolina $+10 \%$ quinoa } & \multicolumn{5}{|c|}{$\mathrm{S}_{6}=80 \%$ semolina $+20 \%$ quinoa } \\
\hline & & & \multicolumn{4}{|c|}{$\mathrm{Q}_{1}=$ Quinoa $100 \%$} & \multicolumn{5}{|c|}{$\mathrm{Q}_{2}=$ Quinoa $90 \%+10 \%$ F.D } \\
\hline \multicolumn{3}{|c|}{$\mathrm{Q}_{3}=$ Quinoa $80 \%+20 \% \mathrm{~F} \cdot \mathrm{D}$} & \multicolumn{9}{|c|}{$\mathrm{Q}_{4}=$ Quinoa $70 \%+30 \%$ F.D(Pregelatinization of starch before adding to the flour.) } \\
\hline Where (F.D.) & $=$ Fraction & D. fr & arley flou & & S & . & & $=$ quinoa & & & \\
\hline
\end{tabular}

\section{Chemical analysis:}

Fat and crud fiber of raw materials and pasta products were estimated according to (A.O.A.C. 2007). Moisture, protein, and ash were determined using (Inframatic 8600 NIR Analyzer with 6-7 narrowband interference filters (6-7 wavelengths).Total carbohydrates were calculated by difference. Calcium, iron, zinc, magnesium, manganese and potassium were determined using ICP (the inductively coupled argon plasma. ICAP 6500 Duo, Thermo Scientific, England.1000mg/l multi. Element certified standard solution, Merck, Germany was used as stock solution, for instrument standardizations). Amino acids were determined after acid hydrolysis according to the method of Pellet and Young, (1980) using amino acid analyzer. Total phenolic were determined, that the prepared extracts were carried out according to Carciochi et. al., (2014) with some modification. Total phenols were determined according to the methodology described by (Renata et. al., 2012). The quantification of phenolic compounds was performed spectrophotometrically by measuring the absorbance in UV-VIS spectrophotometer Shimadzu 1240, at $725 \mathrm{~nm}$, and a gallic acid $(10-100 \mu \mathrm{g} / \mathrm{mL})$ in $95 \%$ ethanol was used for obtaining a 
standard curve. $\beta$-glucan was determined according to the method of ( Aman and Hadden Graham, 1987).

\section{Physical properties of pasta products:}

- The texture of pasta products was determined by Tension-compression cyclic texture-meter Model Dillon.

- The color of pasta products was determined by hunter lab. color.

- Cooking quality of pasta products according to (Yousif et. al., 2012).

The cooking quality of pasta was determined according to Yousif $e t$. al., (2012). Optimum cooking time was the time required for the opaque central core of the noodle to disappear when squeezed gently between two glass plates after cooking. Twenty five gram of noodles were cooked for optimum time in $300 \mathrm{ml}$ boiling water in a beaker rinsed in tap water then drained for 15 min before weighed. Percentage of increased weight was calculated as a cooking yield. Solid contents in the cooking water were determined by drying at $105 \mathrm{C}^{\circ}$ overnight. The cooking loss was expressed as a percentage of the difference between the solid weight and initial dry matter. Volume increase was calculated by dividing the water displacement of cooked pasta on the water displacement of an equivalent amount of uncooked pasta.

Volume increase of cooked pasta $=$

$$
\text { water displacement of an equivalent amount of uncooked pasta }
$$

\section{Sensory evaluation:-}

The prepared pasta samples were evaluated organoleptically according to the method described by Lucia et. al., (2011). Ten panelists in the desert research center were requested to evaluate the most acceptable samples for sensory attributes of non-cooked pasta (Color, Homogeneity, Resistant to break, Overall quality) and cooked pasta (Elasticity, Firmness, Adhesiveness, Color, homogeneity, Odor, taste and over all acceptability). Moreover, a ten-point hedonic rating scale, where 1 corresponded to extremely unpleasant, 10 to extremely pleasant and 5 to acceptable, was used to quantify each attribute. 


\section{Results and discussion:}

\section{Chemical composition of raw materials:}

The chemical composition of raw materials is shown in Table (2). Results showed that the barley flour fraction enriched with $\beta$-glucan, (F.D), recorded the highest percentage of protein followed by quinoa then semolina $(18.88 \pm 0.0, \quad 18.47 \pm 0.01$ and $16.80 \pm 0.02$, respectively). Significant differences were noticed among quinoa flour and other samples. Quinoa revealed higher fat value than the other two types of flour. Ash content of quinoa and F.D was significantly different from that of the semolina flour. In this concern, Jyoti and Chanu, (2018) indicated that quinoa contains high protein, fat and ash contents. Barley fraction D showed highest fiber content compared to the other flour types. Data in table (3) showed that fraction D contained high amount of $\beta$-glucan and protein (17.63\% and $18.88 \%)$ compared to that in barley flour (5.41\% and $14.31 \%)$, respectively. In this concern, this result agrees with the findings of Knuckles et. al., (1992) who indicated that the $\beta$ - glucan percentage in fraction $\mathrm{D}$ was higher than that of the barley flour.

Table (2): Chemical composition of raw materials (g/100g dry wt.basis).

\begin{tabular}{||lccc||}
\hline \multicolumn{1}{|c}{$\begin{array}{c}\text { Chemical } \\
\text { composition }\end{array}$} & \multicolumn{2}{c|}{ Raw materials } \\
semolina & Quinoa & Barley (F.D) \\
\hline Moisture & $14.70 \pm 0.40^{\mathrm{a}}$ & $14.06 \pm 0.23^{\mathrm{a}}$ & $11.37 \pm 0.17^{\mathrm{c}}$ \\
Protein & $16.80 \pm 0.02^{\mathrm{c}}$ & $18.47 \pm 0.01^{\mathrm{b}}$ & $18.88 \pm 0.00^{\mathrm{a}}$ \\
Fat & $01.40 \pm 0.02^{\mathrm{d}}$ & $08.70 \pm 0.08^{\mathrm{a}}$ & $03.47 \pm 0.06^{\mathrm{c}}$ \\
Ash & $01.12 \pm 0.00^{\mathrm{c}}$ & $01.76 \pm 0.01^{\mathrm{b}}$ & $01.84 \pm 0.00^{\mathrm{a}}$ \\
Fiber & $00.09 \pm 0.00^{\mathrm{c}}$ & $00.35 \pm 0.00^{\mathrm{b}}$ & $03.94 \pm 0.01^{\mathrm{a}}$ \\
Carbohydrates & $80.48 \pm 0.01^{\mathrm{a}}$ & $70.72 \pm 0.09^{\mathrm{c}}$ & $71.83 \pm 0.03^{\mathrm{b}}$ \\
$\beta$ - glucan & ----- & ----- & 17.63 \\
\hline
\end{tabular}

The chemical composition of pasta samples:

Data in Table (3) revealed that the highest protein value was in pasta sample $\mathrm{S}_{4}$ containing $70 \%$ semolina $+30 \%$ F.D followed by pasta sample $\mathrm{S}_{7}$ containing $70 \%$ semolina $+30 \%$ quinoa $(17.74 \pm 0.02 \mathrm{a}$, 
$17.76 \pm 0.04 \mathrm{a} \mathrm{g} / 100 \mathrm{~g}$, respectively). It is clear that the addition of Q or F.D, which are rich in protein, increases the protein content of pasta. That was clear in the samples of quinoa pasta where the protein content increased in all samples, the highest protein content (19.52\%) was in sample $\mathrm{Q}_{4}$ $(70 \% \mathrm{Q}+30 \% \mathrm{FD})$. These data are in accordance with the results of Jyoti and Chanu, (2018) who reported that quinoa has a high protein value (12.916.5\%). United States Department of Agriculture (USDA), (2016) reported that quinoa has higher protein content than wheat $(13.21 \mathrm{~g} / 100 \mathrm{~g})$, corn $(9.42$ $\mathrm{g} / 100 \mathrm{~g})$ and barley (12.48 g/100 g). Also, Hussein et. al., (2006) showed that adding barley extractions and different types of barley flour to wheat flour improved the protein content. The pasta sample $\mathrm{S}_{4}$ containing $70 \%$ semolina $+30 \%$ F.D was the highest in ash content, followed by pasta sample $\mathrm{S}_{3}$ containing $80 \%$ semolina $+20 \%$ F.D $(1.73 \%$ and $1.56 \%$, respectively). In quinoa pasta the ash content raised in all samples, the highest percentage was in $\mathrm{Q}_{4}(1.98 \%)$. These data are in harmony with Byung and Steven, (2008), who revealed that barley grains contained 1.5$2.5 \%$ minerals which can be ascribed to F.D or quinoa which have a high content of minerals. These data are similar to the results of Sawsan et. al., (2010), who revealed that the replacement of semolina by barley flour increased the ash level. Pasta samples $S_{7}$ and $S_{6}$ recorded the highest values in fat (2.80\% and $2.69 \%$, respectively); this is due to the high fat content of quinoa. In this concern Jyoti and Chanu, (2018) showed that quinoa seeds oil ranged from 2 to $10 \%$. The highest fiber content was in $\mathrm{S}_{4}$ sample $(1.21 \%)$, while having the lowest carbohydrate content (76.84\%) compared to the other samples. These results agree with Din et. al., (2018), who reported that barley can be used as a good source of soluble dietary fiber ( $\beta$ glucan). The highest fat value was noticed in quinoa pasta. It is clear that the addition of quinoa increases the protein, fat and ash values and reduces the carbohydrates value. These results agree with the findings of Sirpaul et. al., (2019), who reported that quinoa posses adequate amounts of protein, fat, ash, and carbohydrates. Hussein et. al., (2006) showed that adding barley extractions and different types of barley flour to wheat flour improved the protein content. Also, Sawsan et. al., (2010) illustrated that the replacement 


\section{= Fortification Of Pasta With Barley Fraction High B-Glucan And Quinoa Flour}

of semolina by barley flour led to the increase of protein, fiber and ash contents.

Table (3): Chemical composition of pasta samples (on dry wt).

\begin{tabular}{||cccccccc||}
\hline $\begin{array}{c}\text { Pasta } \\
\text { Samples }\end{array}$ & $\begin{array}{c}\text { Moisture } \\
(\%)\end{array}$ & $\begin{array}{c}\text { Protein } \\
(\%)\end{array}$ & $\begin{array}{c}\text { Ash } \\
(\%)\end{array}$ & $\begin{array}{c}\text { Fat } \\
(\%)\end{array}$ & $\begin{array}{c}\text { Fiber } \\
(\%)\end{array}$ & $\begin{array}{c}\text { Carbohydrate } \\
(\%)\end{array}$ & $\begin{array}{c}\text { Total } \\
\text { phenols } \\
(\mathbf{m g} / \mathbf{g})\end{array}$ \\
\hline Semolina pasta & & & & & & \\
S1 & $13.47 \pm 0.02^{\mathrm{e}}$ & $16.26 \pm 0.30^{\mathrm{c}}$ & $1.57 \pm 0.03^{\mathrm{b}}$ & $1.36 \pm 0.07^{\mathrm{c}}$ & $0.08 \pm 0.00^{\mathrm{f}}$ & $81.23 \pm 0.4^{\mathrm{a}}$ & $0.31 \pm 0.005^{\mathrm{a}}$ \\
S2 & $13.23 \pm 0.02^{\mathrm{bcd}}$ & $16.82 \pm 0.13^{\mathrm{b}}$ & $1.53 \pm 0.03^{\mathrm{c}}$ & $1.33 \pm 0.02^{\mathrm{c}}$ & $0.29 \pm 0.02^{\mathrm{e}}$ & $79.99 \pm 0.2^{\mathrm{b}}$ & $0.58 \pm 0.002^{\mathrm{d}}$ \\
S3 & $12.93 \pm 0.06^{\mathrm{a}}$ & $16.92 \pm 0.02^{\mathrm{b}}$ & $1.56 \pm 0.04^{\mathrm{bc}}$ & $2.33 \pm 0.08^{\mathrm{b}}$ & $1.13 \pm 0.00^{\mathrm{a}}$ & $78.06 \pm 0.05^{\mathrm{d}}$ & $0.62 \pm 0.002^{\mathrm{e}}$ \\
S4 & $13.07 \pm 0.02^{\mathrm{ab}}$ & $17.74 \pm 0.02^{\mathrm{a}}$ & $1.73 \pm 0.001^{\mathrm{a}} 2.48 \pm 0.05^{\mathrm{ab}}$ & $1.21 \pm 0.00^{\mathrm{b}}$ & $76.84 \pm 0.03^{\mathrm{e}}$ & $0.69 \pm 0.002^{\mathrm{f}}$ \\
S5 & $13.37 \pm 0.02^{\mathrm{de}}$ & $16.28 \pm 0.04^{\mathrm{c}}$ & $1.30 \pm 0.02^{\mathrm{cd}}$ & $2.59 \pm 0.05^{\mathrm{ab}}$ & $0.17 \pm 0.01^{\mathrm{b}}$ & $79.66 \pm 0.07^{\mathrm{bc}}$ & $0.45 \pm 0.002^{\mathrm{b}}$ \\
S6 & $13.17 \pm 0.02^{\mathrm{bc}}$ & $16.8 \pm 0.04^{\mathrm{b}}$ & $1.28 \pm 0.00^{\mathrm{d}}$ & $2.69 \pm 0.14^{\mathrm{ab}}$ & $0.39 \pm 0.00^{\mathrm{d}}$ & $78.84 \pm 0.16^{\mathrm{cd}}$ & $0.51 \pm 0.003^{\mathrm{c}}$ \\
S7 & $13.27 \pm 0.15^{\mathrm{cd}}$ & $17.76 \pm 0.04^{\mathrm{a}}$ & $1.37 \pm 0.02^{\mathrm{c}}$ & $2.80 \pm 0.16^{\mathrm{a}}$ & $0.69 \pm 0.01^{\mathrm{c}}$ & $77.38 \pm 0.32^{\mathrm{e}}$ & $0.52 \pm 0.002^{\mathrm{c}}$ \\
Quinoa pasta & & & & & & \\
Q1 & $14.15 \pm 0.43^{\mathrm{b}}$ & $17.94 \pm 0.00^{\mathrm{bc}}$ & $1.70 \pm 0.01^{\mathrm{a}}$ & $8.71 \pm 0.35^{\mathrm{a}}$ & $0.24 \pm 0^{\mathrm{d}}$ & $72.17 \pm 0.75^{\mathrm{c}}$ & $0.98 \pm 0.002^{\mathrm{a}}$ \\
Q2 & $11.97 \pm 0.20^{\mathrm{a}}$ & $18.74 \pm 0.56^{\mathrm{b}}$ & $1.78 \pm 32.77^{\mathrm{a}}$ & $4.12 \pm 0.04^{\mathrm{c}}$ & $0.31 \pm 0^{\mathrm{c}}$ & $77.09 \pm 0.73^{\mathrm{a}}$ & $0.47 \pm 0.003^{\mathrm{d}}$ \\
Q3 & $13.32 \pm 0.35^{\mathrm{b}}$ & $19.27 \pm 0.44^{\mathrm{ab}}$ & $1.85 \pm 0.001^{\mathrm{a}}$ & $4.90 \pm 0.15^{\mathrm{b}}$ & $0.52 \pm 0^{\mathrm{b}}$ & $74.54 \pm 0.75^{\mathrm{b}}$ & $0.57 \pm 0.002^{\mathrm{c}}$ \\
Q4 & $13.4 \pm 0.27^{\mathrm{b}}$ & $19.52 \pm 0.4^{\mathrm{a}}$ & $1.98 \pm 0.001^{\mathrm{a}}$ & $5.52 \pm 0.1^{\mathrm{b}}$ & $0.69 \pm 0^{\mathrm{a}}$ & $74.1 \pm 0.66^{\mathrm{b}}$ & $0.58 \pm 0.002^{\mathrm{b}}$ \\
\hline \hline
\end{tabular}

$\mathrm{S}_{1}=100 \%$ semolina $\mathrm{s}_{2}=90 \%$ semolina $+10 \%$ F.D $\quad \mathrm{s}_{3}=80 \%$ semolina $+20 \%$ F.D

$\mathrm{S}_{4}=70 \%$ semolina $+30 \% \mathrm{FD}$.

$\mathrm{S}_{5}=90 \%$ semolina $+10 \%$ quinoa

$\mathrm{S}_{6}=80 \%$ semolina $+20 \%$ quinoa $\mathrm{S}_{7}=70 \%$ semolina $+30 \%$ quinoa

$\mathrm{S}_{7}=70 \%$ semolina $+30 \%$ quinoa Q1= Quinoa 100\%

Q2= Quinoa90\%+ 10\% F.D

$\mathrm{Q}_{3}=$ Quinoa $80 \%+20 \%$ F.D

Q 4= Quinoa70\% +30\% F.D

Where (F.D.) =Fraction D. from barley flour.S= semolina $. \mathrm{Q}=$ quinoa

Regarding total phenols (Table 3) of the semolina pasta, sample $S_{4}$ had the highest phenols content followed by pasta samples $S_{3}$ and $S_{2}(0.69$, 0.62 and $0.58 \mathrm{mg} / \mathrm{g}$, respectively).This may be ascribed to F.D which contains high amounts of total phenols. This result agrees with Emmanuel and Yao Tang, (2017) who reported that whole grain barley contains phytochemicals including phenolic acids, these phytochemicals exhibit strong antioxidants. $S_{6}$ and $S_{7}$ Pasta samples showed higher values of total 
phenols than $S_{1}$ (100\%simolina), this may be due to the high total phenols content of quinoa. All samples of quinoa pasta revealed high content of phenols, the highest of all was $\mathrm{Q}_{1}(0.98 \mathrm{mg} / \mathrm{g})$. These data are in harmony with the study of Jyoti and Chanu, (2018) on six types of quinoa from Chile, they revealed that the studied quinoa seeds have high amounts of phenolic and flavonoid compounds.

Data in Table (4) showed amino acids profile of different prepared pasta. Results revealed that the high valine and methionine values were in pasta $S_{1}, S_{4}$ and $S_{7}$. These increases could be ascribed to the addition of fraction D or quinoa flour. It could be noticed that the $S_{7}$ pasta showed high lysine content $(01.36 \pm 0.11 \mathrm{~b} \mathrm{~g} / 100 \mathrm{~g})$, followed by $\mathrm{S}_{4}$ and $\mathrm{S}_{1}(1.26 \pm 0.08$, $1.15 \pm 0.09$, respectively), while the highest value was for $\mathrm{Q}_{1}(1.78 \%)$. It is clear that the supplementation with quinoa and (F.D) increases the values of the most essential amino acids in pasta products. These results are in harmony with those obtained by Jyoti and Chanu, (2018) who reported that the essential amino acids found in quinoa in good concentrations are like casein (protein of milk). Data disclosed that the addition of F.D (high in $\beta$ glucan) to formulas of pasta increases the percentages of the most essential amino acids of some samples as lysine, threonine and histidine. In this regard, Assem and Nassef (2004) and Sawsan et. al., (2010) indicated that the supplementation of semolina with hull-less barley flour for pasta products (by 10 or 30\%) improved its nutritional value.

The obtained results (Table 4) showed that the highest contents of $\mathrm{Ca}, \mathrm{Cu}, \mathrm{Fe}, \mathrm{Mg}, \mathrm{Mn}$ and $\mathrm{Zn}$ were noticed in pasta sample $\mathrm{Q}_{1}$ (containing $100 \%$ quinoa). In this regard, USDA, (2016) clarified that quinoa contains high mineral content. As well as, Nascimento et. al., (2014) reported that quinoa contains $5.45 \mathrm{mg} \mathrm{Fe} / 100 \mathrm{~g}$. Also, Jyoti and Chanu, (2018) found that quinoa has high level of magnesium. 
- Fortification Of Pasta With Barley Fraction High B-Glucan And Quinoa Flour

Table (4): Amino acids contents and minerals of different pasta

\begin{tabular}{|c|c|c|c|c|c|}
\hline \multirow[b]{2}{*}{ Items } & \multicolumn{5}{|c|}{ Pasta samples } \\
\hline & S1 & S4 & S7 & Q1 & Q3 \\
\hline \multicolumn{6}{|c|}{ Essential amino acids (g/100g protein on dry wt.). } \\
\hline Valine & $3.30 \pm 0.04^{\mathrm{b}}$ & $03.19 \pm 0.07^{\mathrm{a}}$ & $03.18 \pm 0.08^{\mathrm{a}}$ & $\begin{array}{c}02.68 \pm \\
0.08^{\mathrm{b}}\end{array}$ & $02.39 \pm 0.00^{\mathrm{c}}$ \\
\hline Methionine & $01.16 \pm 0.01^{\mathrm{b}}$ & $01.09 \pm 0.02^{\mathrm{ab}}$ & $01.13 \pm 0.02^{\mathrm{a}}$ & $00.69 \pm 0.07^{\mathrm{d}}$ & $00.60 \pm 0.18^{\mathrm{e}}$ \\
\hline Lysine & $01.15 \pm 0.09^{\mathrm{d}}$ & $01.26 \pm 0.08^{\mathrm{c}}$ & $01.36 \pm 0.11^{\mathrm{b}}$ & $01.74 \pm 0.06^{\mathrm{a}}$ & $01.36 \pm 0.10^{\mathrm{b}}$ \\
\hline Phenylalanine & $03.77 \pm 0.04^{\mathrm{a}}$ & $03.34 \pm 0.02^{\mathrm{b}}$ & $03.35 \pm 0.03^{\mathrm{b}}$ & $02.43 \pm 0.01^{\mathrm{c}}$ & $02.11 \pm 0.02^{\mathrm{d}}$ \\
\hline Leucine & $05.60 \pm 0.03^{\mathrm{b}}$ & $04.99 \pm 0.18^{\mathrm{d}}$ & $05.06 \pm 0.05^{\mathrm{c}}$ & $03.90 \pm 0.01^{\mathrm{g}}$ & $03.46 \pm 0.01^{\mathrm{h}}$ \\
\hline Iso leucine & $02.90 \pm 0.04^{\mathrm{b}}$ & $02 . .59 \pm 0.16^{\mathrm{c}}$ & $02.70 \pm 0.14^{\mathrm{a}}$ & $02.26 \pm 0.01^{\mathrm{d}}$ & $01.94 \pm 0.00^{\mathrm{e}}$ \\
\hline Threonine & $01.90 \pm 0.06^{\mathrm{e}}$ & $02.02 \pm 0.06^{\mathrm{c}}$ & $02.07 \pm 0.02^{b}$ & $02.00 \pm 0.01^{\mathrm{d}}$ & $01.76 \pm 0.07^{\mathrm{a}}$ \\
\hline Histidine & $02.18 \pm 0.02^{\mathrm{e}}$ & $02.03 \pm 0.09^{\mathrm{d}}$ & $02.27 \pm 0.12^{\mathrm{b}}$ & $02.38 \pm 0.03^{\mathrm{a}}$ & $02.03 \pm 0.02^{\mathrm{c}}$ \\
\hline \multicolumn{6}{|c|}{ Minerals content } \\
\hline $\mathbf{C a}$ & $3.19 \pm 0.00^{\mathrm{b}}$ & $5.9 \pm 0.0^{\mathrm{f}}$ & $5.36 \pm 0.04^{\mathrm{e}}$ & $44.0 \pm 0.00^{\mathrm{h}}$ & $41.0 \pm 0.00^{\mathrm{g}}$ \\
\hline $\mathbf{C u}$ & $0.04 \pm 0.01^{\mathrm{c}}$ & $.011 \pm .12^{\mathrm{a}}$ & $0.03 \pm 0.0^{\mathrm{b}}$ & $0.59 \pm 0.0^{\mathrm{d}}$ & $0.59 \pm 0.00^{\mathrm{d}}$ \\
\hline $\mathbf{F e}$ & $1.06 \pm 0.37^{\mathrm{b}}$ & $1.03 \pm 8.5^{\mathrm{a}}$ & $3.73 \pm 0.08^{\mathrm{d}}$ & $5.73 \pm 0.26^{\mathrm{g}}$ & $6.43 \pm 0.47^{\mathrm{h}}$ \\
\hline Mg & $3.19 \pm 0.07^{\mathrm{a}}$ & $4.75 \pm 0.0^{\mathrm{d}}$ & $3.61 \pm 0.05^{\mathrm{b}}$ & $7.78 \pm 0.01^{\mathrm{g}}$ & $8.71 \pm 0.33^{\mathrm{h}}$ \\
\hline Mn & $0.10 \pm 0.00^{\mathrm{c}}$ & $0.15 \pm 0.1^{\mathrm{e}}$ & $0.08 \pm 0.00^{\mathrm{b}}$ & $0.1 \pm 0.002^{\mathrm{c}}$ & $0.11 \pm 0.00^{\mathrm{d}}$ \\
\hline Zn & $0.18 \pm 0.00^{\mathrm{c}}$ & $0.51 \pm 0.4^{\mathrm{f}}$ & $0.23 \pm 0.0^{\mathrm{e}}$ & $3.1 \pm 0.00^{\mathrm{g}}$ & $3.2 \pm 0.00^{\mathrm{h}}$ \\
\hline $\mathbf{C a}$ & $3.19 \pm 0.00^{\mathrm{b}}$ & $5.9 \pm 0.0^{f}$ & $5.36 \pm 0.04^{\mathrm{e}}$ & $44.0 \pm 0.00^{\mathrm{h}}$ & $41.0 \pm 0.00^{\mathrm{g}}$ \\
\hline $\mathbf{C u}$ & $0.04 \pm 0.01^{\mathrm{c}}$ & $.011 \pm .12^{\mathrm{a}}$ & $0.03 \pm 0.0^{\mathrm{b}}$ & $0.59 \pm 0.0^{\mathrm{d}}$ & $.0 .59 \pm 0.00^{\mathrm{d}}$ \\
\hline
\end{tabular}

$\mathrm{S}_{1}=$ semolina $100 \%$ as control, $\mathrm{S}_{4}=$ semolina $70 \%+30 \%$ F.D, $\mathrm{S}_{7}=$ semolina $70 \%+30 \% \mathrm{Q}$,

$\mathrm{Q}_{1}=$ quinoa $100 \%$ as control, $\mathrm{Q}_{3}=$ quinoa $80 \%+20 \%$ F.D.

F.D =Fraction D. from barley flour.

Physical properties:

Hunter lab color:

Data in figure (2) revealed that the highest lightness value (L) noticed in pasta sample $S_{7}$, while pasta samples $S_{4}$ was the lowest value. The highest redness value (a) noticed in pasta sample $S_{4}$, while pasta sample $\mathrm{S}_{6}$ recorded the lowest value. The pasta sample $\mathrm{S}_{1}$ was the highest yellowness value (b) followed by $S_{7}$, however the pasta sample $S_{4}$ recorded 
the lowest. This may be ascribed to barley flour which could be the cause of the darker color. These results are in agreement with the findings of Marconi, et. al., (2000), Sawsan, et. al., (2010) and Garsa, (2017), who reported that color values of all barley pastas are similar, however, they were darker (low $\mathrm{L}^{*}$ values and higher $\mathrm{a}^{*}$ values) and less yellow (low $\mathrm{b}^{*}$ values) than durum wheat pasta which could be ascribed to the addition of fraction D or quinoa flour. The results are in agreement with Schoenlechner et. al., (2010), Susanna et. al., (2012), Fiorda et. al., (2013), Andrew, (2014), and Sharma et. al., (2018), who reported that a-value (redness), was found to increase by increasing the content of quinoa. It can be concluded that the amount of quinoa flour added to pasta significantly affects redness. Bright yellow pasta is achieved by having both high $b^{*}$ values and low $a^{*}$ values.

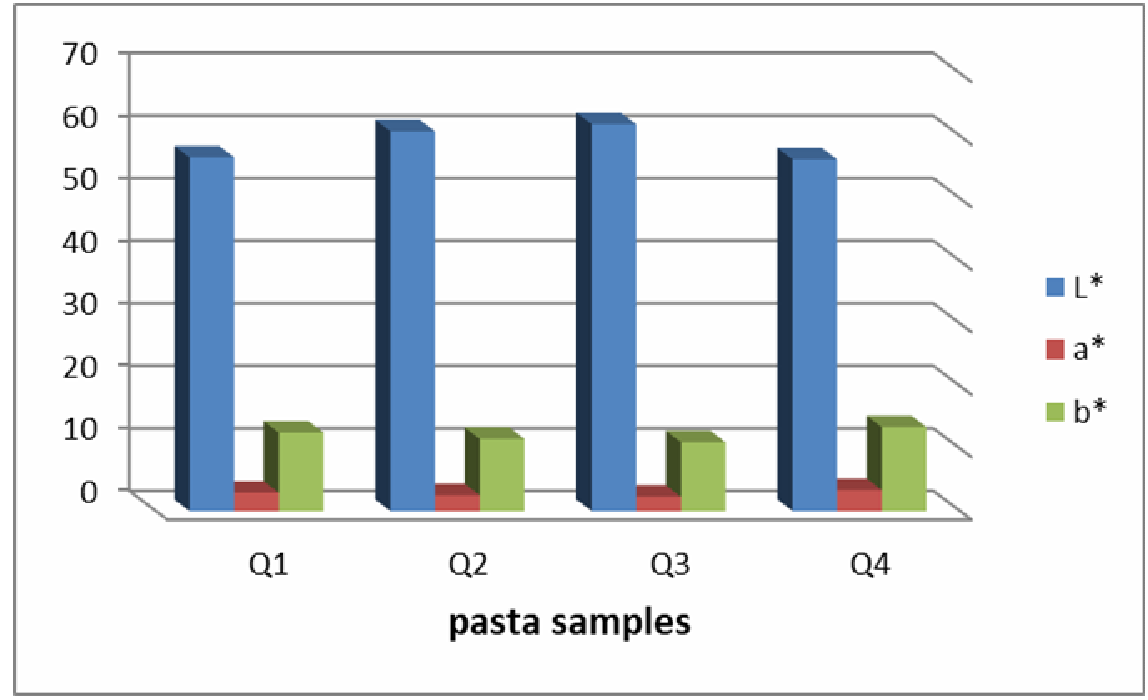

Figure (2): Hunter lab color of semolina and Quinoa pasta

$\mathrm{S}_{1}=$ semolina $100 \% \mathrm{~S}_{2}=90 \%$ semolina+ $10 \%$ F.D S $3=80 \%$ semolina+ $20 \%$ F.D S $4=70 \%$ semolina+ 30\% F.D

$\mathrm{S}_{5}=90 \%$ semolina $+10 \%$ quinoa $\mathrm{S}_{6}=80 \%$ semolina $+20 \%$ quinoa $\mathrm{S}_{7}=70 \%$ semolina $+30 \%$ quinoa

$\mathrm{Q}_{1}=100 \%$ quino $\mathrm{Q}_{2}=90 \%$ quinoa $+10 \%$ F.D $\mathrm{Q}_{3}=80 \%$ quinoa+ $20 \%$ F.D

$\mathrm{Q}_{4}=70 \%$ quinoa+ $30 \%$ F.D S= semolina $\mathrm{Q}=$ quinoa Where (F.D.) =Fraction D. from barley flour

\section{Texture of un- cooked pasta:}

The textural property was determined by measuring the force required to break pasta. The higher value of peak force required in gram, to 
breakdown the sample, means higher in the breaking stress of the sample. It is clear from (Fig.3) that the highest breaking stress value was noticed in pasta sample $\mathrm{S}_{4}\left(70 \%\right.$ semolina $+30 \%$ F.D), followed by pasta sample $\mathrm{Q}_{4}$ $\left(80 \%\right.$ quinoa $+30 \%$ F.D), meanwhile the pasta sample $\mathrm{S}_{7}(70 \%$ semolina + $30 \%$ quinoa) was the lowest. This may be ascribed to the increase of the quinoa contents that led to the reduction in breaking stress. This result agrees with Mastromatteo et. al., (2011), who reported that quinoa decreases the firmness of pasta. F.D gave the pasta sample high breaking stress because of its low starch content and high $\beta$-glucan. These data are in agreement with Fiorda et. al., (2013) and Sharma et. al., (2018), who reported that breaking stress decreased by increasing the starch proportion. Also F.D has hydrocolloid attributes which gave the pasta dough higher texture levels during baking than the other samples. This result agrees with Beatriz et. al., (2014), who found that texture score increased by increasing hydrocolloids especially guar gum.

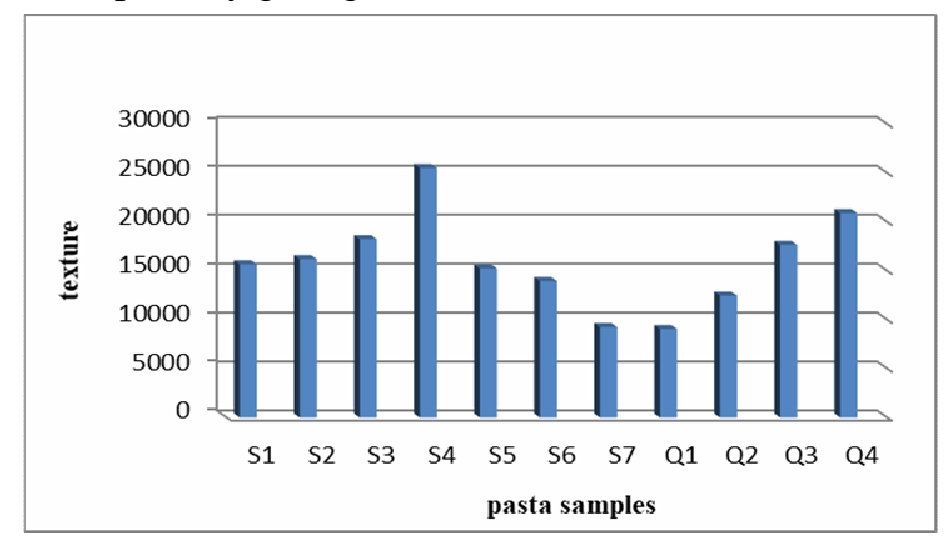

Fig 3: The texture of semolina and quinoa pastas.

$\mathrm{S}_{1}=$ semolina $100 \% \mathrm{~s}_{2}=90 \%$ semolina $+10 \%$ F.D $\mathrm{S}_{3}=80 \%$ semolina $+20 \%$ F.D

$\mathrm{S}_{4}=70 \%$ semolina $+30 \%$ F.D $\mathrm{S}_{5}=90 \%$ semolina $+10 \%$ quinoa

$\mathrm{S}_{6}=80 \%$ semolina $+20 \%$ quinoa $\mathrm{S}_{7}=70 \%$ semolina $+30 \%$ quinoa

$\mathrm{Q}_{1}=100 \%$ Quino $\mathrm{Q}_{2}=90 \%$ Quinoa+ $10 \%$ F.D

$\mathrm{Q}_{3}=80 \%$ Quinoa+ 20\% F.D $\mathrm{Q}_{4}=70 \%$ Quinoa+ 30\% F.D

$\mathrm{S}=$ semolina $\mathrm{Q}=$ quinoa Where (F.D.) =Fraction $\mathrm{D}$. from barley flour 
$\overline{\underline{ }}$ Pج.P. مجلة بحوث التربية النوعية- عدد 1ه - أبريل

\section{The cooking quality of semolina and quinoa pasta:}

\section{a- Semolina pasta:}

Data in table (5) and (Fig.4) showed that the highest cooking time value was noticed in pasta sample $S_{1}$ containing $100 \%$ semolina followed by pasta sample $S_{2}$ containing $90 \%$ semolina $+10 \%$ F.D. $(15.17 \pm 0.11,14.87$ $\pm 0.15 \mathrm{~min}$., respectively), meanwhile the pasta sample $S_{7}$ took the lowest cooking time $(5.83 \pm 0.14 \mathrm{~min})$. This may be ascribed to the addition of quinoa flour which weakens the gluten net. The highest cooking loss (Fig.4) was in pasta samples $S_{7}$ followed by $S_{6}(18.94 \pm 0.01,18.51 \pm 0.12$, respectively), while the pasta sample $S_{2}$ recorded the lowest value (6.35 \pm 0.02). This result agrees with Zahran et. al., (2004) and Garsa, (2017), who illustrated that the high levels of total dietary fiber and $\beta$-glucan in barley resulted in an increase in the water holding capacity of pasta.

The highest volume increase values were in pasta samples $\mathrm{S}_{7}, \mathrm{~S}_{4}$ and $\mathrm{S}_{3}(299.67 \pm 0.21,299.33 \pm 0.42$ and $299.33 \pm 1.12$, in succession), while pasta sample S2recorded the lowest value $(223.33 \pm 1.05)$. This may be attributed to the water retention behavior of F.D. This result is in harmony with the findings of Garsa, (2017), who showed that high fiber pasta had high volume and weight.

The highest weight increase was seen in pasta sample $S_{7}$, while the pasta sample $S_{5}$ recorded the lowest value $(173.33 \pm 0.56$ and $106.67 \pm 0.21$, respectively). These data are in agreement with Silva et. al., (2013) and Padalino et. al., (2016) who found that hydrocolloids have high water binding capacity.

\section{b- Quinoa pasta:}

Regarding the cooking time of quinoa pasta, sample $\mathrm{Q}_{4}$ showed the highest value, while pasta sample $\mathrm{Q}_{1}$ was the lowest $(6.60 \pm 0.13,3.83 \pm 0.17$ min, in succession). These data are in an agreement with Beatrize et. al., (2014), padalino et. al., (2011) and padalino et. al., (2016) and Chillo et. al., (2008), which attributed the increase in the speed of water penetration of the core to the physical disruption of the gluten matrix caused by the addition of non gluten material. 
The pasta sample $\mathrm{Q}_{1}$ recorded the highest value in cooking loss followed by $\mathrm{Q}_{2}$, however the pasta sample $\mathrm{Q}_{4}$ recorded the lowest value $(18.49 \pm 0.01,11.19 \pm 0.06$ and $10.63 \pm 0.20 \%$, respectively). This result agree with the findings of Andrew, (2014), who revealed that the increase in cooking loss can be attributed to the gluten structure weakness (as a result of the addition of a non-gluten material), which allowed more solids from the noodles to leach out into the cooking water, also can be attributed to starch damage, as the increased levels of starch damage led to an increase in cooking loss. Also the addition of F.D, which is a hydrocolloid, led to a decrease in cooking loss. These data are in agreement with Beatrize et. al., (2014), padalino et. al., (2011) and padalino et. al., (2016), who showed that the hydrocolloids improve cooking quality and decrease cooking loss. The pasta sample $\mathrm{Q}_{4}$ recorded the highest value in volume increase (Fig.5), while pasta sample $\mathrm{Q}_{1}$ recorded the lowest value (350.00 \pm 0.00 and $299.67 \pm 0.21$, respectively). The highest weight increase (Fig.5) was seen in pasta sample $\mathrm{Q}_{4}$, while the pasta sample $\mathrm{Q}_{1}$ was the lowest $(229.17 \pm 0.11$ and $157.03 \pm 0.09$, in succession). These results are in harmony with Beatrize, et. al., (2014) padalino et. al., (2016), who reported that hydrocolloids are compounds with great molecular masses, has the ability to bind large amounts of water. 
مجلة بحوث التربية النوعية - عدد 1ه - r.r.

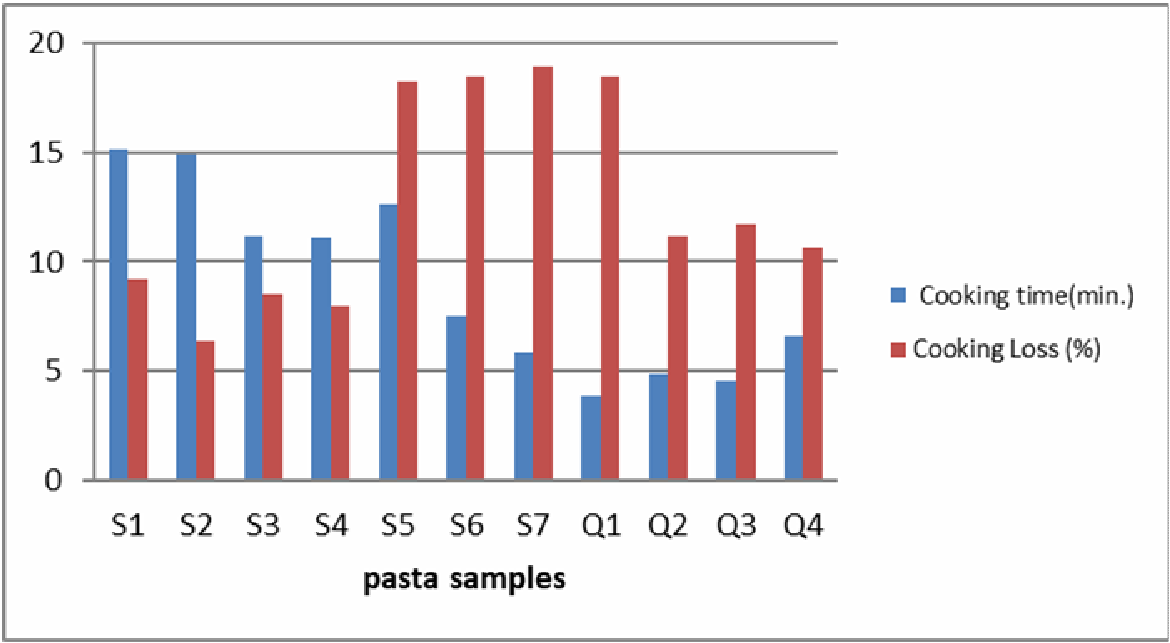

Fig 4: cooking time and cooking loss of semolina and quinoa pasta.

$\mathrm{S}_{1}=$ semolina $100 \%$

$\mathrm{s}_{2}=90 \%$ semolina $+10 \%$ F.D

$\mathrm{S}_{3}=80 \%$ semolina $+20 \%$ F.D

$\mathrm{S}_{4}=70 \%$ semolina $+30 \%$ F.D

$\mathrm{S}_{5}=90 \%$ semolina $+10 \%$ quinoa

$\mathrm{S}_{6}=80 \%$ semolina $+20 \%$ quinoa

$\mathrm{S}_{7}=70 \%$ semolina $+30 \%$ quinoa

$\mathrm{Q}_{1}=100 \%$ Quinoa

$\mathrm{Q}_{2}=90 \%$ Quinoa+ $10 \%$ F.D

$\mathrm{Q}_{3}=80 \%$ Quinoa $+20 \%$ F.D $\quad \mathrm{Q}_{4}=70 \%$ Quinoa $+30 \%$ F.D

$\mathrm{S}=$ semolina

$\mathrm{Q}=$ quinoa 


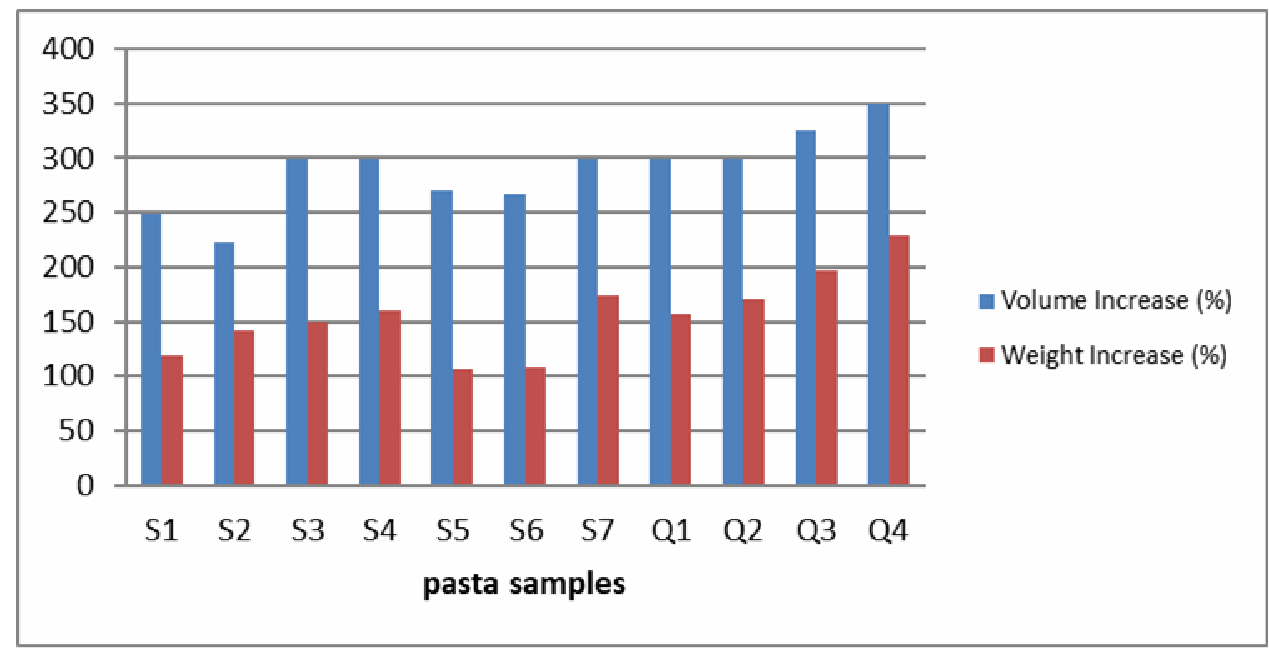

Fig 5: volume and weight increase of semolina and quinoa pasta

$\mathrm{S}_{1}=$ semolina $100 \%$ $\mathrm{s}_{2}=90 \%$ semolina+ $10 \%$ F.D $\mathrm{s}_{3}=80 \%$ semolina $+20 \%$ F.D

$\mathrm{S}_{4}=70 \%$ semolina $+30 \%$ F.D $\quad \mathrm{S}_{5}=90 \%$ semolina $+10 \%$ quinoa

$\mathrm{S}_{6}=80 \%$ semolina $+20 \%$ quinoa $\mathrm{S}_{7}=70 \%$ semolina $+30 \%$ quinoa

$\mathrm{Q}_{1}=100 \%$ Quinoa

$\mathrm{Q}_{2}=90 \%$ Quinoa+ $10 \%$ F.D

$\mathrm{Q}_{3}=80 \%$ Quinoa+ 20\% F.D

$\mathrm{Q}_{4}=70 \%$ Quinoa+ $30 \%$ F.D

$\mathrm{S}=$ semolina

$\mathrm{Q}=$ quinoa (F.D.) =Fraction D. from barley flour 
$\overline{\overline{1}}$

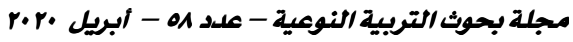

Table (5): Cooking quality of semolina and quinoa pasta.

\begin{tabular}{||ccccc||}
\hline \hline Samples & $\begin{array}{c}\text { Cooking } \\
\text { time(min.) }\end{array}$ & Cooking Loss (\%) & Volume Increase (\%) & Weight Increase (\%) \\
\hline \multicolumn{5}{|c}{ Semolina pasta } \\
$\mathbf{S}_{\mathbf{1}}$ & $15.17 \pm 0.11^{\mathrm{e}}$ & $9.17 \pm 0.02^{\mathrm{d}}$ & $248.33 \pm 2.79^{\mathrm{b}}$ & $119.00 \pm 0.37^{\mathrm{c}}$ \\
$\mathbf{S}_{\mathbf{2}}$ & $14.87 \pm 0.15^{\mathrm{e}}$ & $6.35 \pm 0.02^{\mathrm{a}}$ & $223.33 \pm 1.05^{\mathrm{a}}$ & $141.67 \pm 0.56^{\mathrm{d}}$ \\
$\mathbf{S}_{\mathbf{3}}$ & $11.17 \pm 0.06^{\mathrm{c}}$ & $8.49 \pm 0.03^{\mathrm{c}}$ & $299.33 \pm 1.12^{\mathrm{d}}$ & $150.00 \pm 0.37^{\mathrm{e}}$ \\
$\mathbf{S}_{\mathbf{4}}$ & $11.10 \pm 0.04^{\mathrm{c}}$ & $8.01 \pm 0.07^{\mathrm{b}}$ & $299.33 \pm 0.42^{\mathrm{d}}$ & $160.33 \pm 0.56^{\mathrm{f}}$ \\
$\mathbf{S}_{\mathbf{5}}$ & $12.60 \pm 0.13^{\mathrm{d}}$ & $18.25 \pm 0.02^{\mathrm{e}}$ & $270.33 \pm 1.73^{\mathrm{c}}$ & $106.67 \pm 0.21^{\mathrm{a}}$ \\
$\mathbf{S}_{\mathbf{6}}$ & $7.53 \pm 0.15^{\mathrm{b}}$ & $18.51 \pm 0.12^{\mathrm{f}}$ & $267.33 \pm 0.92^{\mathrm{c}}$ & $108.67 \pm 0.21^{\mathrm{b}}$ \\
$\mathbf{S}_{\mathbf{7}}$ & $5.83 \pm 0.14^{\mathrm{a}}$ & $18.94 \pm 0.01^{\mathrm{g}}$ & $299.67 \pm 0.21^{\mathrm{d}}$ & $173.33 \pm 0.56^{\mathrm{g}}$ \\
$\mathbf{Q u i n o a}$ & & & \\
$\mathbf{Q}_{\mathbf{1}}$ & $3.83 \pm 0.17 \mathrm{a}$ & $18.49 \pm 0.01 \mathrm{~d}$ & $299.67 \pm 0.21 \mathrm{a}$ & $157.03 \pm 0.09 \mathrm{a}$ \\
$\mathbf{Q}_{\mathbf{2}}$ & $4.83 \pm 0.11 \mathrm{~b}$ & $11.19 \pm 0.06 \mathrm{~b}$ & $299.67 \pm 0.21 \mathrm{a}$ & $171.43 \pm 0.46 \mathrm{~b}$ \\
$\mathbf{Q}_{\mathbf{3}}$ & $4.57 \pm 0.15 \mathrm{~b}$ & $11.71 \pm 0.00 \mathrm{c}$ & $325.00 \pm 1.83 \mathrm{~b}$ & $196.83 \pm 0.28 \mathrm{c}$ \\
$\mathbf{Q}_{\mathbf{4}}$ & $6.60 \pm 0.13 \mathrm{c}$ & $10.63 \pm 0.20 \mathrm{a}$ & $350.00 \pm 0.00 \mathrm{~d}$ & $229.17 \pm 0.11 \mathrm{~d}$ \\
\hline
\end{tabular}

$\mathrm{S}_{1}=$ semolina100\% $\quad \mathrm{S}_{2}=90 \%$ semolina+ $10 \%$ F.D $\quad \mathrm{S}_{3}=80 \%$ semolina+ $20 \%$ F.D

$\mathrm{S}_{4}=70 \%$ semolina+ 30\% F.D $\quad \mathrm{S}_{5}=90 \%$ semolina+ $10 \%$ quinoa $\quad \mathrm{S}_{6}=80 \%$ semolina $+20 \%$ quinoa

$\mathrm{S}_{7}=70 \%$ semolina+ $30 \%$ quinoa $\quad \mathrm{Q}_{1}=100 \%$ Quinoa $\quad \mathrm{Q}_{2}=90 \%$ Quinoa+ $10 \%$ F.D

$\mathrm{Q}_{3}=80 \%$ Quinoa+ 20\% F.D $\quad \mathrm{Q}_{4}=70 \%$ Quinoa+ 30\% F.D

Sensory evaluation of pasta:

a-Cooked and non- cooked semolina pasta:

Data presented in Table (6) illustrated that the highest color value was noticed in pasta sample $S_{1}$ containing $100 \%$ semolina followed by $S_{2}$ containing $90 \%$ semolina $+10 \%$ F.D, meanwhile the pasta sample $\mathrm{S}_{4}$ containing $70 \%$ semolina $+30 \%$ F.D recorded the lowest value (9.5 \pm 0.67 and $7.65 \pm 1.18$, respectively). This may be ascribed to F.D. These results agree with hunter lab values (Fig.2) and with Garsa, (2017), who showed that barley flour is the main factor of color in dark pasta.

The applied seven pasta samples didn't exhibit any significant difference in homogeneity, considering that the highest homogeneity value 
was in pasta sample $S_{1}$ (control) followed by pasta sample $S_{2}$ containing 90 $\%$ semolina $+10 \%$ F.D, while the pasta sample $\mathrm{S}_{4}$ recorded the lowest value $(9.45 \pm 0.83,8.90 \pm 0.84$ and $7.80 \pm 1.23$, in succession).

The highest value of break resistance in pasta was sample $\mathrm{S}_{1}$ followed by $S_{2}$, while the lowest one was $S_{7}(9.20 \pm 0.75,8.90 \pm 0.66$ and $7.65 \pm 0.53$, in succession). This may be ascribed to the addition of quinoa which seems to be the cause of the reduction in breaking stress. This result agrees with Mastromatteo et. al., (2011), who reported that quinoa, decreases the firmness of pasta. Moreover F.D gave the pasta sample high breaking stress because of its low starch content. These data is in harmony with Fiorda et. al., (2013) and Sharma et. al., (2018), who reported that the breaking stress decreased by increasing the starch proportion. In addition to that, F.D has hydrocolloid attributes which gave the dough pasta higher texture levels during drying than other samples. This result agrees with Beatriz et. al., (2014), who found that the texture score increased by increasing hydrocolloid.

The highest value for the overall quality of pasta was pasta sample $S_{1}$ followed by $S_{2}$, however, the pasta sample $S_{4}$ had the lowest value $(14.35 \pm 0.82,13.65 \pm 0.94$ and $11.35 \pm 1.94$, respectively). This may ascribed to presence of fraction D (hydrocolloid) which is improved the quality of pasta. This result agree with padalino et. al., 2011, who reported that The presence of hydrocolloids improved the sensorial properties of pasta samples.

Meanwhile the highest value of elasticity was of sample $S_{1}(9.35 \pm$ $0.2)$ followed by $S_{5}(8.45 \pm 0.6)$, while the pasta samples $S_{7}$ and $S_{6}$ were the

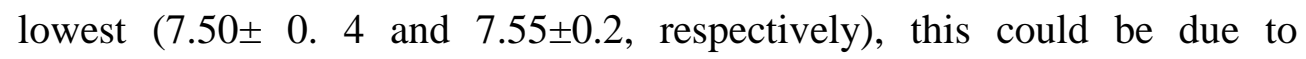
chewiness (Chewiness is the energy required to chew solid food until it is ready for swallowing), that's may be the reason why pasta samples fortified by quinoa, especially high levels, were chewier than the control pasta. These data are in agreement with Andrew, (2014) who revealed that pasta with the highest levels of chewiness contained the largest amounts of quinoa (20- 30 $\%$ ) flour. It could be noticed that $S_{1}(100 \%$ semolina) showed high firmness 
value $(9.10 \pm 0.88)$ followed by $S_{2}(8.50 \pm 0.88)$, while the pasta sample $S_{7}$ recorded the lowest $(7.40 \pm 0.94)$. This effect on firmness may be attributed to the quinoa flour. Also in barley F.D samples this may be ascribed to barley F.D (high in $\beta$-glucan). These results agree with Padalino et. al., (2011), who reported that the increase in the oat bran content led to a decrease in the elasticity and firmness of the spaghetti when compared to the control sample.

No significant differences were observed between all pasta samples in Adhesiveness considering that the highest adhesiveness value was in pasta sample $S_{1}(8.80 \pm 1.48)$ followed by $S_{5}(8.60 \pm 0.84)$. It could be noticed that pasta sample $S_{1}$ showed significantly high color value after cooking compared with the other samples $(9.35 \pm 0.63)$ followed by pasta sample $\mathrm{S}_{5}(8.55 \pm 0.76)$, while the pasta sample $\mathrm{S}_{4}$ recorded the lowest $(7.95 \pm 0.59)$. These results are similar to Garsa, (2017), who showed that barley flour is responsible for the darker color in pasta. Meanwhile, the darker color in pasta containing quinoa may be because of the pigments as mentioned before or the high ash content. This result is in harmony with Andrew, (2014), who illustrated that the redness increased ( $a^{*}$ value increased) significantly $(\mathrm{p}<0.05)$ as more quinoa flour was added. It can be concluded that the amount of quinoa flour added to pasta significantly affects redness.

The highest value of the homogeneity attribute was noticed in pasta $S_{1}$ followed by $S_{5}$, however pasta sample $S_{6}$ was the lowest $(9.50 \pm 0.67$, $8.60 \pm 0.94$ and $7.95 \pm 1.01$, respectively). It is clear that there was no significant difference between all pasta samples in Odor. The highest taste value was noticed in pasta sample $S_{1}(23.70 \pm 3.47)$ followed by $S_{2}$ $(22.90 \pm 1.79)$, while the pasta sample $S_{4}$ was the lowest $(20.30 \pm 2.6)$. The pasta sample $S_{1}(100 \%$ semolina) recorded the highest overall acceptability value followed by $\mathrm{S}_{5}\left(90 \%\right.$ semolina $+10 \%$ quinoa) and $\mathrm{S}_{2}(90 \%$ semolina $+10 \%$ F.D), meanwhile pasta sample recorded the lowest $\mathrm{S}_{4}$ containing 70 $\%$ semolina $+30 \%$ F.D $(14.5 \pm 0.85,13.8 \pm 1.23,13.6 \pm 1.07$ and $12.0 \pm 1.41$, in succession). 
جدول 7 بالعرض 
ב

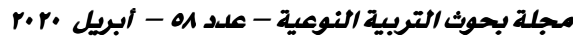

\section{Cooked and non- cooked quinoa pasta:}

Data shown in Table (7) shows the Sensory evaluation of cooked and non-cooked pasta made with Quinoa. No significant differences were found between all the pasta samples, considering that the highest color value before cooking was noticed in pasta sample $\mathrm{Q}_{1}$ containing $100 \%$ quinoa followed by $\mathrm{Q}_{2}$ containing $90 \%$ quinoa+10\%F.D, while the pasta sample $\mathrm{Q}_{4}$ containing $70 \%$ quinoa+30\% F.D recorded the lowest value. This may be ascribed to F.D which may be the cause of the darker color. These results agree with Sawsan et. al., (2010) and Garsa, (2017) who showed that the barley flour is the main factor of the dark color in pasta.

Concerning the pasta homogeneity attribute, the applied seven pasta samples in table (7) were not able to exhibit any significant difference in homogeneity, considering that the highest homogeneity value was in pasta

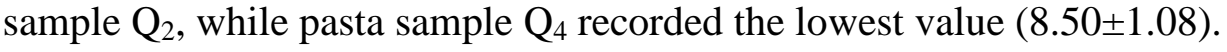

No significant differences were found between the pasta samples in break resistance and the overall quality, considering that the highest value was noticed in pasta sample $\mathrm{Q}_{1}(8.5 \pm 1.08,13.5 \pm 1.08$, respectively), while the $\mathrm{Q}_{4}$ recorded the lowest $(7.95 \pm 1.01,12.7 \pm 1.03$, in succession).

elasticity, firmness, homogeneity and taste, the applies seven pasta samples were not able to exhibit any significant difference keeping in mind that the highest value was in pasta sample $\mathrm{Q}_{1}(7.65 \pm 1.11,8.1 \pm 0.88$, $8.4 \pm 0.97,22.4 \pm 0.44$, respectively), while the lowest values of pasta samples $\mathrm{Q}_{3}(6.9 \pm 1.1)$ in elasticity, $\mathrm{Q}_{2}(6.9 \pm 1.1)$ in firmness, $\mathrm{Q}_{3}(8.2 \pm 1.01)$ in homogeneity. Also, the applies seven pasta samples were not able to exhibit any significant difference keeping in mind that the highest Odor value was in pasta sample $\mathrm{Q}_{2}$, however pasta sample $\mathrm{Q}_{3}$ recorded the lowest $(13.80 \pm 1.316,12.50 \pm 0.972$, in sucession). This could due to F.D and guar gum which are rebonsible of improving in the sensory evauation. These results agree with padalino et. al., (2011), Beatrize et. al., (2014), and padalino et. al., (2016), who reported hydrocolloids improved the sensory evaluation of pasta samples, Elasticity, firmness, homogeneity, Oder and taste, no significant between all pasta samples. 
The highest adhesiveness value was noticed in pasta sample $\mathrm{Q}_{1}$ followed by $\mathrm{Q}_{4}$, while the pasta sample $\mathrm{Q}_{2}$ was the lowest $(8.15 \pm 1.16$, $8.1 \pm 1.02$ and $7.95 \pm 1.26$, respectively). This may ascribe to increase F.D percentage and decrease quinoa flour percentage then decrease starch amount which pregelatinized and improved the quality of pasta. This result is similar to Padalino et. al., 2011, who reported that the increase of the oat bran percentage and consequent decreasing of the amount of maize flour used decreased the quantity of pregelatinized maize starch available to structure the dough. Finally, no significant difference between all pasta sample in most parameters keeping in mind that pasta sample Q1 which contain $100 \%$ quinoa recorded the highest values. These may ascribe to quinoa flour plus F.D and guar gum (hydrocolloids) able to form a good network. This result is harmony with Mastromatteo et. al., (2011) and Sharma et. al., (2018), who suggested that quinoa flour, shows a good ability to form a physical network such as that formed by gluten. Also, agree with Beatrize et. al., (2014), padalino et. al., (2011) and padalino et. al., (2016), who reported hydrocolloids, improved the sensory evaluation and quality of pasta samples. 


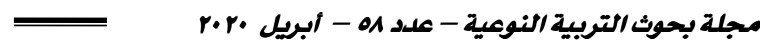

جدول V جالعرض 


\section{CONCLUSION}

Finally, results of the consumer acceptance test indicated that panelists significantly $(\mathrm{p}<0.01)$ preferred the control pasta. Since all pasta variations received scores above neutral, it was determined that the addition of FD and quinoa flours does not adversely affect the acceptability of pasta products.

In conclusion, the pasta product with the most beneficial ratio of FD and quinoa flours is that containing $70 \%$ semolina $+30 \%$ F.D followed by pasta sample $\mathrm{S}_{7}$ containing $70 \%$ semolina $+30 \%$ quinoa. Formula $\mathrm{S}_{4}$ and $\mathrm{S}_{7}$ had the highest protein content and the best amino acid profile, along with increased fat and fiber content. Its cooking loss was found to be in an acceptable range, and besides having lower values of cohesiveness, the texture attributes were not adversely affected by fortification. The color characteristics of pasta $\mathrm{S}_{4}$ were also closest to that of the control, leading to a high level of visual acceptability. The semolina pasta sample $S_{4}$ was the highest phenols content. This may ascribed to F.D (high in $\beta$ - glucan) which contains high amounts of total phenols. It could be noticed that pasta $S_{7}$ showed high lysine content.

All samples of quinoa pasta revealed high content of phenols, the highest of all was $Q_{1}$. It is clear that the supplementing with quinoa and (F.D) increase the values of most essential amino acids in pasta products. Addition of F.D (high in $\beta$-glucan) to formulas of quinoa pasta increases the percentages of essential amino acids of samples as lysine, threonine and histidine. The high $\mathrm{Ca}, \mathrm{Cu}, \mathrm{Fe}, \mathrm{Mg}, \mathrm{Mn}$ and $\mathrm{Zn}$ contents were noticed in pasta samples $\mathrm{Q}_{1}$ containing $100 \%$ quinoa.

Accordingly, it can be determined that the addition of quinoa flour and FD had the greatest effect on fortifying wheat pasta. Quinoa pasta $\left(Q_{1}\right.$, $\mathrm{Q}_{2}, \mathrm{Q}_{3}$ and $\mathrm{Q}_{4}$ ) had high nutritional value than semolina pasta. Data concluded the possibility of producing pasta relatively higher in fiber, $\beta$ glucan and protein without considerable bad effects on its cooking quality and sensory properties, and also has many benefits for health of diabetes, high cholesterol patients and heart diseases. 


\section{References:}

- A.O.A.C. (2007).Official Method, of Analysis of the Associa Official Analytical Chemists, 18 th. Edition, 2005, current through Revision 2. (Editors. Dr .William horwitz, Dr George, Latimer, jr.), whashington, USA.

- Aman, P. and Graham, H. (1987). Analysis of total and insoluble mixed-linked $(1 \rightarrow 3),(1 \rightarrow 4)-\beta$-D-glucans in barley and oats. J. Agric. Food Chem., 35: 704709 .

- Andrew, D. Clarke.and Melissa Slinkard (2014). Fortification of pasta with chickpea quinoa flour. Thesis, University of Missouri.

- Assem, N.H. and A.E. Nassef.(2004). Chemical and physical studies in producing spaghetti macaroni from unirradiatedand irradiated hull-less barley flour. Arab Universities J. of Agric. Sci., 12(2): 609-619.

- Atef, A.; Abou-Zaid; El-Faham, S.Y.and Wafaa, H. E. (2014). Use of Quinoa Meal to Produce Bakery Products to Celiac and Autism Stuffs. International Journal of Science and Research, 3(9):1344-1354.

- Beatriz, S. S,; Hug, D. S.; Maria, A. T. and Carlos, A. O. (2014). Design of a premix for making gluten free noodles International Journal of Nutrition and Food Sciences, 3(5): 488-492.

- Byung-Kee, B. and Steven, E. U. (2008). Barley for food: Characteristics, improvement, and renewed interest. Journal of Cereal Science, 48: 233-242.

- Carciochi, R. A.; Manrique, G. D. and Dimitrov, K. (2014). Changes in phenolic composition and antioxidant activity during germination of quinoa seeds (Chenopodium quinoa Willd.), International Food Research Journal, 21(2): 767773.

- Cavallero, A. Empilli, S.; Brighenti, F.; Stanca, M. (2002). High B - glucan barley fractions in bread making and their effects on human glycemic response. J.Cereal Sic 36:59-66.

- Chillo, S.; Laverse, J.; Falcone, P.M.; Protopapa, A. and Del Nobile M.A. (2008). Influence of the addition of buckwheat flour and durum wheat bran on spaghetti quality. J Cereal Sci 47:144-52.

- Costas, G. B. and Marta, S. I. (2007). Functional Food and nutraceuticals series, Functional Food Carbohydrates.

- Din, A.; Chughtai, M. F. J.; Khan, M. R. K.; Shahzad, A.; Khaliq, A. and Nasir, M. A. (2018). Nutritional and functional perspectives of barley $\beta$-glucan. International Food Research Journal, 25(5): 1773-1784. 
- Duda, A. ; Adamczak, J. ; Chełmińska, P. and Juszkiewicz, J. (2019). Quality and Nutritional/Textural Properties of Durum Wheat Pasta Enriched with Cricket Powder Foods, 8 (46) .

- Emmanuel, I. and Yao Tang, S. (2017). Bioactive phytochemicals in barley. Journal of Food and Drug Analysis, 2 5:148-161.

- FAO. (1999). Production Year Book. Vol.53:165- 170.

- Fiorda, F. A. ; Soares, J. M.S.; Silva, F.A.; Grosmann, M.V. (2013). Micro structure, texture and colour of gluten-free pasta made with amaranth flour, cassava starch and cassava bagasse. LWT-Food Science and Technology, 54:132-138.

- Gallegos-Infante, J.A.; Rocha-Guzman, N.E.; GonzalesLaredo, R.F.; OchoaMartínez, L.A.; Corzo, N.; Bello-Perez, L.A.; Medina-Torres, L. and PeraltaAlvarez, L.E. (2010). Quality of spaghetti pasta containing Mexican common bean flour (Phaseolus vulgaris L.). Food Chem. 119, 1544-1549.

Garsa, A. A. S. (2017). Preparation and quality evaluation of pasta substituted with hull-less barley. Australian Journal of Basic and Applied Sciences, 11(1): 98-106.

- Gopalakrishnan,J.; Menon, R. and Padmaja, G. (2019). Nutritional and Functional Characteristics of Protein-Fortified Pasta from Sweet Potato. Food and Nutrition Sciences, 2, 944-955.

- Holtekjolen, K. Knutsen, S. (2011). antioxidant activity and phenolics in breads with added barley flour. In: reedy VR, Watson, R.R and Patel, V.B. (Eds) Flour and breads and their fortification in health and disease prevention. Academic Press, Elsevier. London, Burlington, San Diego pp.355-363ISBn 9780123808868 Academic Press, Elsevier.

- Hussein, A.M.S.; Helmy, I.M. and Mostafa, B.E. (2006). Effect of barley flour and some of their functional ingredients. Minufiya J. Agric. Res., 31(4): 877888 .

- Inglett, G.E. and Chen, D. (2011). Contents of phenolics and flavonoids and antioxidant activities in skin, pulp, and seeds of Miracle fruit. Journal of Food Science, 76(3): 479-482.

- International Pasta Organization [Internet]. Oct. ( 2012) [Accessed 2014 Mar 4]. Available from: www.internationalpasta.org.

- Jancurova, M.; Minarovičova, L. and Dandar A. (2009). Quinoa - a review. Czech J. Food Sci., 27: 71-79. 
- Jyoti, G. and Chanu, H. (2018). QUINOA (Chenopodium quinoa Willd.) - the forgotten golden grain.International journal of food and nutritional sciences, 7 , No. 1.

- Knuckles, B.E.; Chiu, M.M.and Betschart,A.A.(1992). $\beta$-Glucan enriched fractions from laboratory-scale dry milling, J.Cereal chem., 69 (2) 198-202.

- Lahouar, L. ; EL Arem, A. and ACHOUR, L. (2016). Bioactive compounds in whole grain barley: Nutraceutical properties and health benefits. Journal of Bioresources, 1 (1): 5-15.

- Lee, A.R.; Ng, D.L.; Zivin, J. and Green, P.H. (2007). Economic burden of a gluten-free diet. Journal of Human Nutrition and Dietetics, 20:423-430.

- Lucia, P.; Marcella, M.; Grazia,S. (2011). Formulation Optimization of GlutenFree Functional Spaghetti Based on Maize Flour and Oat Bran Enriched in $\beta$ Glucans, Materials, 4: 2119-2135.

- Madhumitha, S.; Prabhasankar, P.(2011). Influence of additives on functional and nutritional quality characteristics of black gram flour incorporated pasta. $\mathbf{J}$ Texture Stud 42:441-450.

- Marconi E, Carcea M. 2001. Pasta from nontraditional raw materials. Cereal Food World 46(11):522-30.

- Mastromatteo, M.; Chillo, S. Iannetti, M.; Civica, V. and Del Nobile, M.A. (2011). Formulation optimization of gluten-free functional spaghetti based on quinoa, maize and soy flours. International Journal of Food Science and Technology, 46, 1201-1208.

- Nascimento, A. C.; Mota, C.; Coelho, I.; Gueifao, S.; Santos, M.; Matos, A. S.; Gimenez, A.; Lobo, M. Samman, N. and Castanheira, I. (2014). Characterisation of Nutrient Profile of Quinoa (Chenopodium quinoa), Amaranth (Amaranthus causatus), and Purple Corn (Zea mays L.) Consumed in North of Argentina: Proximates, Minerals and Trace Elements. Journal of Food Chem., Vol. 148, pp. 420-426.

- National Research Council, (1989). Lost Crops of the Incas: Little-Known Plants of the Andes with Promise for Worldwide Cultivation. Washington:

- National Academy Press.

- Padalino, L.; Mastromatteo; M. Sepielli, G. and Del Nobile M. A. (2011). Formulation Optimization of Gluten-Free Functional Spaghetti Based on Maize Flour and Oat Bran Enriched in $\beta$-Glucans. Materials. 2011:2119-2135. 
- Padalino, L.; Amalia, C. and Matteo, Al. (2016). Overview on the General Approaches to Improve Gluten-Free Pasta and Bread. Foods , 5, 87; 1-18.

- Pellet, P.L. and Young,V.V.R. (1980). Nutritional evaluation of protein foods.Published by the United Nation University.

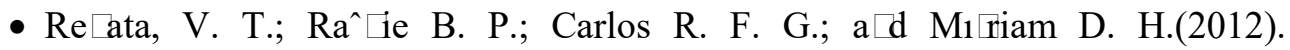
Microencapsulation of Flaxseed Oil by Spray Drying: Effect of Oil Load and Type of Wall Material. Drying Technology, 30: 1491-1501.

- Rose, D.J.; DeMeo, M.T.; Keshavarzian, A. and, Hamaker, B.R. (2007).Influence of dietary fiber on inflammatory bowel disease and colon cancer: importance of fermentation pattern. Nutr Rev. 65(2):51-62.

- Sawsan, Y. E.F.; Eid, A. A. E.H.; Hussein, K. A. (2010). Barley Flour and Durum Flour Blends in Macaroni Product. Australian Journal of Basic and Applied Sciences, 4(12): 6169-6178.

- Schoenlechner, R.; Drausinger, J.; Ottenschlaeger, V.; Jurackova, K.; Berghofer, E. (2011). Functional properties of gluten-free pasta produced from amaranth, quinoa and buckwheat. Plant Food Hum. Nutr., 65, 339-349.

- Sharma, A.; Surbhi, S.; Narendra, K. J. and Lalit, K. M.(2018). Quality protein maize based pasta supplemented with quinoa, soy and corn starch International Journal of Chemical Studies, 6(3): 3158-3165.

- Sima ,P.; Vannucci, L. and Vetvicka, V. (2018). $\beta$-glucans and cholesterol (Review). International journal of molecular medicen.

- Silva, E.; Birkenhake, M.; Scholten, E.; Sagis, L.M.C.; van der Linden, E. (2013). Controlling rheology and structure of sweet potato starch noodles with high broccoli powder content by hydrocolloids. Food Hydrocoll. 2013, 30, 4252.

- Sirpaul, J.; Wenqiang, Li.; Zhenbiao, Y. and Shikui Song. (2019). Quinoa: In Perspective of Global Challenges. Agronomy , 9, 176.

- Susanna, S. and Prabhasankar, P. (2012). A study on development of Gluten free pasta and its biochemical and immunological validation. LWT-Food Science and Technology, 50:613-621.

- USDA: National Nutrient Database for Standard. (2016) .cited January 11, 2017], available from: https://ndb.nal.usda.gov/ndb/search/list

- Yousif, E.I. ; Gadallah, M.G.E.; Afaf, M. S.(2012). Physico-chemical and rheological properties of modified corn starches and its effect on noodle quality, Annals of Agricultural Science, 57(1), 19-27. 
- Zahran, G.A.H.; N.M. Abd El-Motaleb and O.S.R. Shams.( 2004). Chemical and biological functional aspects of pasta rich in dietary fiber and B-glucan. Egyptian Journal of Agricultural Research, 82(3): 13-25.

- Zhao, Y.H.; Manthey, F.A.; Chang, S.K.; Hou, H. Yuan, S.H. (2005). Quality characteristics of spaghetti as affected by green and yellow pea, lentil, and chickpea flours. J Food Sci., 70(6):S371-76. 


\section{تعريز المكرونة بدقيق الشعير الذي تم زيادة نسبه البيتا جلوكان فيه و دقيق الكينها}

\section{الالنص العرببي}

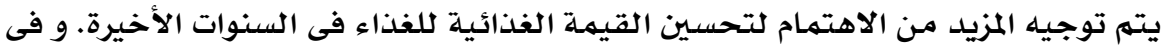

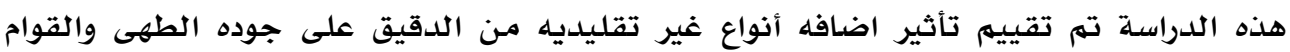

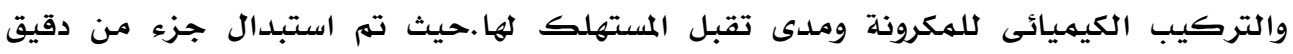

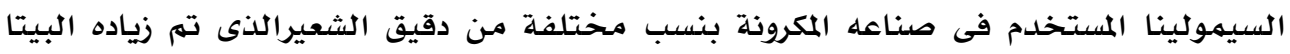

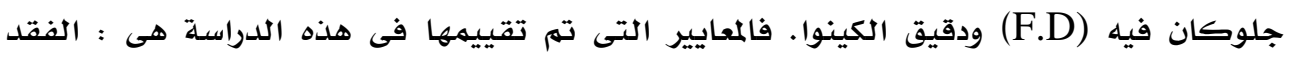

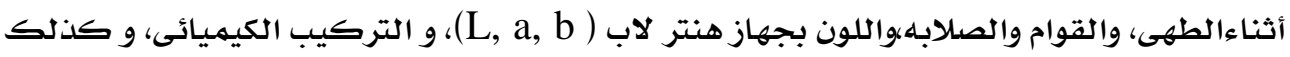

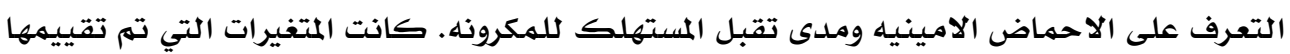

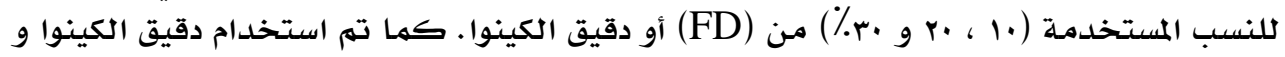

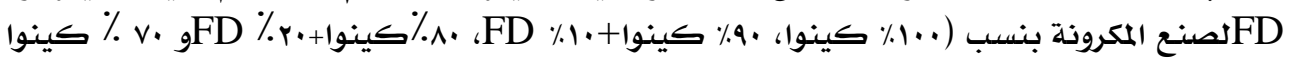

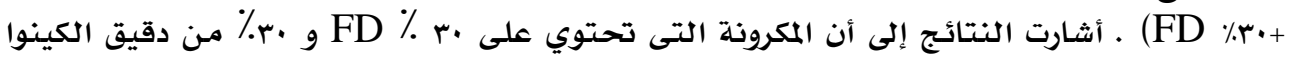

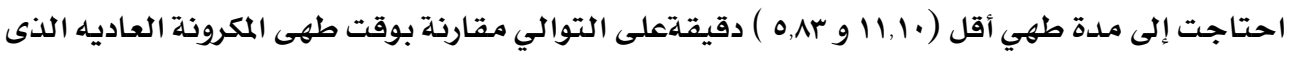

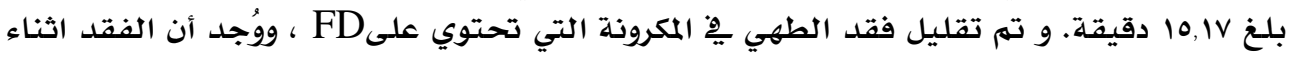

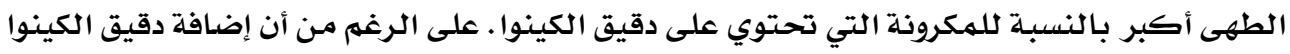

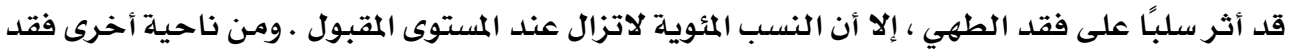

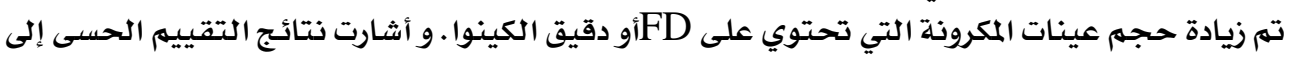

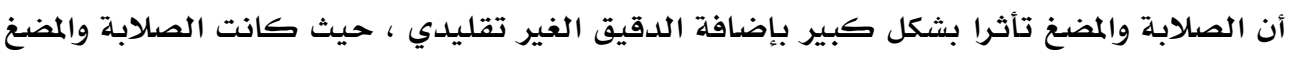

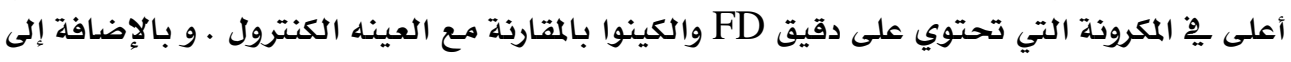

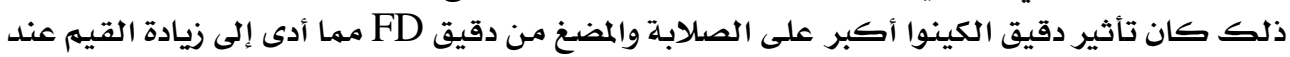

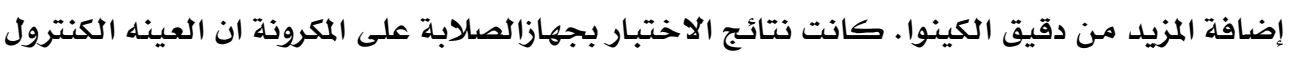

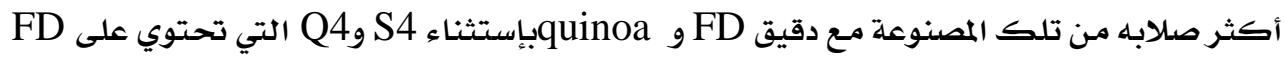

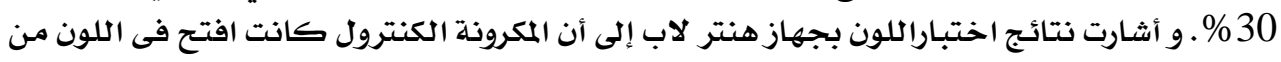

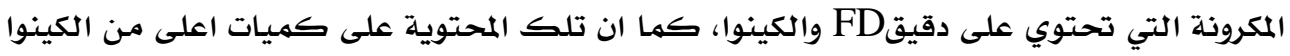

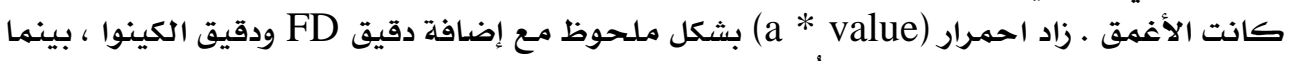

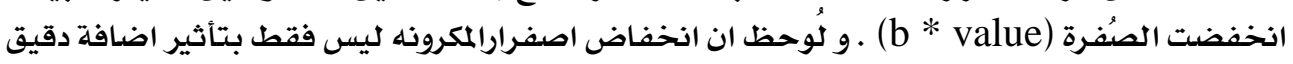

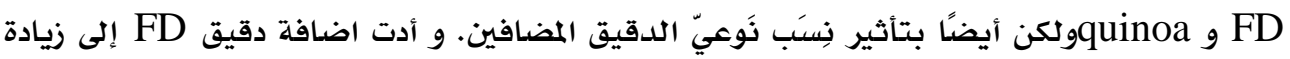

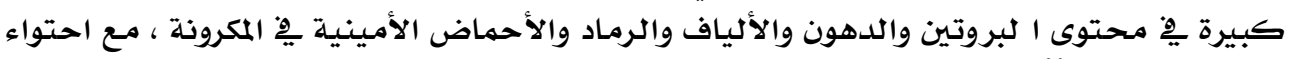

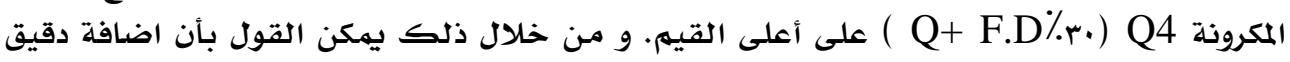

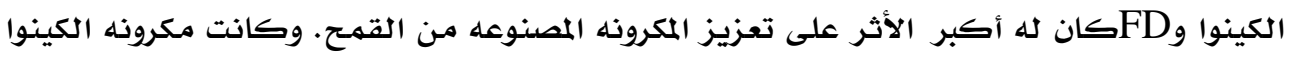

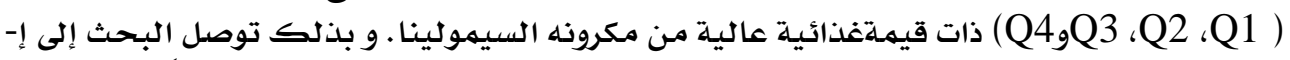

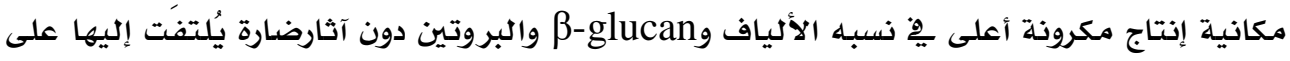

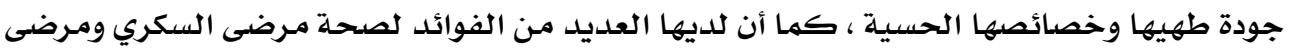
الكوليسترول المرتفع وأمراض القلب. 